\title{
THE ÆTIOLOGY AND TREATMENT OF PROSTATITIS AND VESICULITIS
}

By W. K. IRWIN

\section{Discussion}

The President said she felt sure there would be a good discussion, and those who were engaged in male V.D. work would feel very grateful to Mr. Irwin.

Dr. T. Anwyl Davies expressed his cordial thanks to Mr. Irwin for his paper, which he had listened to with much interest. Naturally, it was a topic of the utmost importance in male clinic work, because the majority of cases were those of prostatitis and vesiculitis.

For some time he carefully studied the anatomy of the vesicles and the prostate, and the result of that study had confirmed what he had thought for a long time and what was supported by his own statistics at the Whitechapel clinic, namely, that vesiculitis was a far commoner condition than it was usually thought to be. For many years it had been known that posterior urethritis was a very common complication. Statistics on the subject varied, and one often wondered what the correct percentage of posterior urethritis might be; he was sure, however, it was much higher than most practitioners thought. He believed that the majority of cases of gonococcal posterior urethritis had some accompanying degree of vesiculitis. Many had a vesiculitis before evidence developed of a prostatitis, and this was easily understood after studying the anatomy of the part.

Prostatitis and vesiculitis were two of the most difficult conditions in the specialty to treat, and he was therefore very interested to hear about McCarthy's latest method of injecting into the prostatic tissue. Instances of this method, and indeed of any injections or operations on the vesicle and prostate, which he had seen had been very disappointing. He hoped to hear, this evening, of some more suitable methods of treatment. 


\section{BRITISH JOURNAL OF VENEREAL DISEASES}

Major F. C. Doble also thanked Mr. Irwin very much for his paper. He would like to hear Mr. Irwin's view as to the way in which the prostate and vesicles became infected; whether it was by direct extension from the anterior to the posterior urethra, or through the lymphatics. Mr. Kenneth Walker, some years ago, when talking here on the mode of spread of infections, said that infection in these cases was vi $\hat{a}$ the lymphatics; $\mathrm{Mr}$. Walker had a patient with carcinoma of the tip of the penis, and he amputated that organ, but previously he injected methylene blue into the urethra, and said the lymphatics carried the infection, and that it was not borne by direct extension along the urethra.

Dr. H. M. HANSChELl thanked Mr. Irwin for his interesting paper. Besides warm posterior urethral lavage, the stock recommended treatment for prostatitis and vesiculitis was massage. One school insisted on very gentle massage. This would induce increased peripheral circulation of blood and lymph, as does the hot lavage, but scarcely emptying or drainage. The hearty vigorous school pressed and rubbed hard, and undoubtedly expressed some of its contents from prostate or vesicle, at the cost of pain to the patient: and it was still a contrasting fact that no other gland in the body, with the exception of the pustule in the sebaceous gland, was ever so treated when inflamed. No one has yet rubbed a parotitis or an inguinal adenitis. He (Dr. Hanschell) practised massage only for diagnostic purposes.

Mr. Hamish Nicol said he was particularly interested in what Mr. Irwin said about stenosis of the internal meatus, and asked what treatment that gentleman carried out in those cases. With regard to vesiculitis, sometimes he found the vesicle was very difficult to feel, though in some one was aware of an obvious thickening. $\mathrm{He}$ had never encountered cases which required vesiculectomy, and his cases of vesiculitis had appeared to do well; that might be because he had not yet had a very serious instance of it.

Mr. Ambrose KING said that he also had been very much interested in Mr. Irwin's paper, and he would like to refer to one or two points which appealed to him particularly.

He was very glad to hear Mr. Irwin say he thought the incidence of vesiculitis and prostatitis together in 


\section{ÆTIOLOGY AND TREATMENT OF PROSTATITIS}

cases of posterior urethritis showed a very high proportion; possibly most of the cases were so infected. That view received support from tests he and his colleagues had carried out. The fact that no clinical evidence could be found of infection of the prostate or vesicles did not mean that those organs were not infected. To discover this it was necessary to examine the prostatovesicular contents, when it would be found that in many cases infection had occurred without any clinical sign of it being evident. And he confessed to feeling some doubt as to whether even those cases in which, clinically, the urethritis was purely anterior escaped infection of prostate and seminal vesicles. In association with Dr. Price he took a small series of patients with very mild urethritis in whom only the first specimen of urine showed signs of infection, and in whom the symptoms and signs cleared up in three or four days under the usual irrigation treatment-cases of purely anterior urethritis by ordinary standards. These were followed up for two or three weeks until in each case the urine had been clear for ten days or more, and at the end of that time they felt justified in massaging gently the prostate and seminal vesicles, having first irrigated the urethra, and obtained prostato-vesicular secretion. Dr. Price cultured the latter, and from all the cases he isolated the gonococcus. $\mathrm{He}$, the speaker, did not know how the gonococcus reached that area, whether by surface spread, or by the blood stream or by the lymphatics. In those cases there was definite evidence that the gonococcus was able to reach the prostate and seminal vesicles, although the clinical evidence suggested that the infection was limited to the anterior urethra.

With regard to gonococcal iritis, he noticed Mr. Irwin's remark that he did not think ophthalmic surgeons in general were alive to the frequency with which this condition might be due to old-standing and latent gonorrhœa. He had seen a number of cases of that type in the last two years, and his impression was that the ophthalmic surgeons were fully aware of the gonococcus as a possible cause of relapsing iritis, but those surgeons were so convinced of the ineffectiveness of the ordinary methods of treatment of the pelvic foci of infection that they did not think it worth while even to have the cases investigated. They sometimes treated them with gono- 


\section{BRITISH JOURNAL OF VENEREAL DISEASES}

coccal vaccine as a palliative measure, but the impression was that the condition would recur, even after years, the eye being progressively damaged with each recurrence.

He had seen Dr. McCarthy carry out his treatment of prostatitis in New York Post-graduate Hospital, eighteen months ago, and he, Mr. King, persuaded Dr. Anwyl Davies to get one of McCarthy's instruments and the accessories with the view to carrying out the procedure. He himself had tried to carry it out, but-probably because of faulty technique-his patients did not seem as pleased with him as Dr. McCarthy's were with him. Apart from that, however, the idea underlying this procedure struck him as being fundamentally unsound. Chronic prostatitis he regarded not as a generalised and freely communicating infection throughout the whole gland, but as a condition which involved pocketing and faulty drainage in certain areas; and therefore the procedure of pushing a needle through the median wall of the prostatic lobe and injecting electrargol blindly did not seem likely to succeed, as one could not be confident of reaching the really infected areas.

He had been struck in the last few years with the number of references in the literature to the frequency of infestation of the prostate with the trichomonas vaginalis. In a limited number of cases which he himself had investigated he did not come upon a single case of it, and he would like to know what was the experience of other members on this point.

Colonel L. W. HARrison declared that he had not any intention of taking part in this discussion, but he had heard one or two remarks which were somewhat challenging.

Mr. Irwin had condemned self-irrigation, and in doing so he seemed somewhat inconsistent with subsequent remarks, as he attributed to the clinic system-where self-irrigation was largely carried out-the chief credit for the reduction of the incidence of cases of stricture. His own view was that if a patient was taught properly the results of self-irrigation were as good as when the surgeon did it himself.

He would like to hear Mr. Irwin's opinion on the value of diathermy in clearing up infections of the prostate and vesicles. Most members agreed that diathermy did not 


\section{ÆTIOLOGY AND TREATMENT OF PROSTATITIS}

act by killing the gonococcus in gonococcal prostatitis and vesiculitis, but by promoting drainage. And, with all respect to Dr. Hanschell, he thought that prostatic massage was good, the latter promoting drainage, and that the addition of diathermy to these measures gave the best results. This had also been well shown in metastatic infections.

Dr. A. E. W. McLachlan said that he had listened with interest to Mr. Irwin's paper, and also to the remarks of the subsequent speakers.

He was surprised that little reference had been made to the importance of influenza as an ætiological factor in the production of metastatic prostatitis; such cases were generally referred to the V.D. clinics, and only careful history-taking and examination revealed the true ætiology, and averted the stigma of sexual irregularities. There were a number of references in the literature.

Another ætiological factor was syphilis, rare, but none the less interesting. Recently he had seen two cases. One simulated the ordinary chronic prostatitis, but with very marked diurnal and nocturnal frequency. Gonorrhoal and other bacterial infections were excluded by repeated cultural tests. Anti-specific treatment alone was sufficient to bring about symptomatic and clinical cure. The second case simulated senile enlargement of the prostate, with marked residual urine. Under antisyphilitic treatment the prostate decreased in size and the residual urine diminished to less than half an ounce.

In the treatment of prostatitis, prostatic massage was, he considered, of the greatest importance. The great difficulty was the decision of how early could one commence prostatic massage in acute cases. If one delayed too long there was danger of the prostatic ducts becoming sealed up: their later emptying was then a matter of difficulty. If, on the other hand, prostatic massage was commenced too early there was grave danger of flaring up the local prostatitis and precipitating metastatic complications. He considered that each individual case must be judged on its merits, and that no hard and fast rule could be laid down as to the correct time to institute prostatic massage. He considered that diathermy was of value in acute prostatitis. 


\section{BRITISH JOURNAL OF VENEREAL DISEASES}

In the treatment of chronic vesiculitis he had had some small experience with vasostomy: he had noticed no benefit in 25 per cent. of the cases. Vasostomy could only be regarded as an attempt to clear the mouth of a blocked vesicle: routine treatment must be carried out afterwards.

With regard to the chemotherapy of prostato-vesiculitis, he had tried various drugs in a series of cases: sulpharsphenamine, calcium salts, etc. Some of the cases had shown symptomatic relief and marked improvement, but the average rate of cure was little better than with the ordinary conservative measures.

The PRESIDENT said she felt personally grateful to all who had entered into this discussion, as it was only by such airing of views and stating of experiences that progress was made in this work; that she had said before, but it would bear repetition.

She had already said she knew little of the male side of this subject, but it was quite clear that prostatitis and vesiculitis must be prolific sources of infection and re-infection of married women. Yet, when asked, the women mostly declared emphatically that there was nothing the matter with their husbands, and some said they were sure their husbands would not come up for treatment. Hence in so many instances one's treatment of the women was abortive, for soon after curing a case it came again with a relapse.

The President said she had also been interested in $\mathrm{Mr}$. Ambrose King's reference to the trichomonas organism in the prostate. It was present in most purulent discharges of women, and these women declared that their husbands were in rude and vigorous health; and she did not know how they escaped prostatic and urethral infection with the organism. She would be glad to know if there was any more information about the presence of the organism in infections of the prostate.

Mr. IRwIN, in reply, thanked all who had spoken for their kind reception of his remarks. He agreed with everything which Dr. Anwyl Davies said.

The result of the treatment of vesicles was, in many instances, disappointing; there was nothing in venereal disease work more disappointing than some of these cases. If the patient had chronic arthritis which was obviously due to the condition of the vesicle, the only 


\section{ÆTIOLOGY AND TREATMENT OF PROSTATITIS}

sound treatment was removal of the vesicle; one would not think of allowing an abscess to persist in any other part of the body without removal. He had carried out this removal in three cases, with good results, and in all of them he had previously carried out other treatments without lasting good result.

Major Doble asked as to the mode of extension of the infection. In some cases the extension occurred by way of lymphatics, while in others he thought direct spread was the mode. In a number he thought both methods were responsible.

Dr. Hanschell had spoken about removal of the prostate in these cases. If this were done, the "cure" might prove worse than the disease, though the prostate could be taken away if a line of cleavage existed.

Perhaps prostatic massage had been abused as much as anything in medicine. When, in I920, he first took up V.D. work he was shocked at some of the treatments then in vogue. Patients with acute prostatitis were given vigorous prostatic massage every day, and the speaker could not imagine a more damaging procedure. Still, if properly carried out and in suitable cases, it could be very beneficial. One must do it oneself, not trust to the male nurse, as it was necessary to appreciate the line of prostatic ducts, and to empty the gland. Massage, if not correctly done, might cause damage even in chronic cases.

He thought Dr. Hanschell showed himself to be too pessimistic in his remarks about vesiculitis. There were a large number of cases of vesiculitis which could be cured without operation, namely, by a proper emptying of the vesicle, and in the right direction.

He was sure some ophthalmic surgeons missed the character of some cases of gonococcal iritis. One ophthalmologist had sent him a large number of these cases, which he recognised as different from the usual run of iritis cases, and that gentleman had never been wrong in his diagnosis of them. In every case which he so suspected the speaker had been able to demonstrate the presence of the gonococcus or post-gonorrhœal organisms.

In answer to Colonel Harrison, he had never found self-irrigation do good, nor self-injections either. He had watched the results in numerous cases, and many of the patients would have been much better if they had not 


\section{BRITISH JOURNAL OF VENEREAL DISEASES}

had any local treatment at all; sandal-wood oil, say, and large quantities of bland fluids would have done them much more good.

He quite agreed as to the benefit of diathermy in promoting drainage, especially if combined with massage. Vasotomy he did not regard as a success. As long as a patient had a vesicle which was not emptying itself normally, no good was done by frequent washing out. 